\title{
Proposing Researcher Brand Equity Index in Hospitality and Tourism
}

\begin{abstract}
Purpose: This study proposes a holistic model to rank and evaluate researchers' performance. This holistic model is developed by focusing on brand equity, which includes three components of perceived quality, brand image, and brand loyalty.
\end{abstract}

Design/methodology/approach: To show how the model works, two pseudo cases are presented.

Findings: This model encourages researchers to conduct more interdisciplinary research and collaborate with researchers from diverse backgrounds. Since the model includes publication attributes identified by researchers in the publication processes, it allows researchers to strengthen their brand equity score or performance. .

Practical Implications: The model is applicable not only to the fields of hospitality and tourism but also to other disciplines.

Originality/Value: As one of the first study in the field, this research introduces a holistic model to rank and evaluate researchers' performance.

Keywords: individual ranking, performance evaluation, brand equity, tourism, hospitality 


\section{INTRODUCTION}

The main purpose of this study is to propose a holistic individual ranking model in hospitality and tourism research called the Researcher's Brand Equity Index. Ranking of researchers has always been an interesting field of inquiry for researchers and institutions since it helps them to evaluate their position within academic communities. There are a number of studies ranking authors or researchers in various disciplines (Bouyssou \& Marchant, 2016; Li, Wang, Zhang, Lei, Ma, \& Chen, 2014; Marchant, 2009; Soutar, Wilkinson, \& Young, 2015; Zhou, Orshanskiy, Zha, \& Giles, 2007). As shown in the journal ranking literature (Koseoglu, 2018), research on ranking individuals has generated its own literature and academic community due to the importance of individual rankings on researchers' performance appraisals and headhunting for institutions, government agencies, and publishers. These studies have focused on developing new ranking models, experimenting with these models in different disciplines, or discussing the usefulness of these models (Law, 2017; Rickman \& Winters, 2016; Yang, Hong, Yin, \& Davison, 2015).

The existing ranking models have two main constructs; research quantity and research quality (Dev, Parsa, Parsa, \& Bujisic, 2015). Research quantity is an objective measure that includes the counting of publications based on the contribution of an author. In multi-authored publications, this contribution has been identified as the number of publications or fractional scores (Furrer, Thomas, \& Goussevskaia, 2008; Koseoglu, Yildiz, \& Ciftci, 2018). Research quality is a less objective measure than research quantity, yet it is still used to rank and evaluate researchers. To measure research quality, the number of citations and/or indexes derived from citations has been used in individual rankings. However, these models neglect to measure an author's contribution based on structure of collaboration, type of contribution, methodology, and funding 
for the work. Additionally, they do not provide a holistic perspective for the ranking and performance appraisal of researchers. To meet this need for a holistic ranking, this study proposes a new approach called the Researcher's Brand Equity Index (RBEI), which borrows the term "brand equity" from the field of business and management. The main logic behind this is that all researchers generate their own brand, which impacts both their career path and the position of the institutions where they have worked. Therefore, measurement of the brand equity (Aaker, 1996) of a researcher may help develop a holistic individual ranking model that can be beneficial for researchers and institutions. The following section provides an overview of the current approaches to individual rankings. The next section explains the proposed model using the RBEI approach. The operationalization of the model is then presented and discussed. Finally, conclusions and suggestions for future studies are provided.

\section{LITERATURE REVIEW}

\section{Overview of Individual Ranking Models}

Researchers and institutions have developed models to rank and evaluate the performance of individuals by considering mainly publication numbers or contribution level (quantity) of researchers, the quality of published articles, or a combination of these two perspectives. Therefore, three approaches — quantity-based models, quality-based models, and hybrid models— emerge in the literature and in practice (Dev et al., 2015; Law, 2017).

Quantity-based models: The main metric in these models is publication count. There are two types of quantity-based models to rank researchers in the literature. The first model is based on publication numbers, or researchers' appearance in a given period (Law, 2017). The second is based on scores calculated by authorship order (Furrer et al., 2008). The quantity-based models are simple and commonly used in individual rankings (Law, 2017) or performance appraisals of 
faculty's research performance. These methods may be objective, but they do not illustrate a clear picture of the influence and impact researchers generate in the literature and/or academic communities. Based on the experience of present study's authors', these quantity-based methods are used by many institutions to evaluate faculty's research performance. However, in the practice of performance appraisal of researchers, formal guidelines established by an institution can improve objectivity. If institutions do not provide formal guidelines for this process, the subjectivity increases, and the methods become questionable. This may influence levels of satisfaction among researchers. Regardless, these quantify-based methods ignore how researchers are influential and create an impact, and are therefore not holistic in their approach.

Quality-based models: In the individual ranking literature or performance appraisal of researchers, the determination of the quality of a publication is unclear. A publication's impact, often used to measure quality, is determined mainly by two indicators: citations numbers (Adkins \& Budd, 2006; Benckendorff, \& Shu, 2019) and/or journal impact factors (Amin \& Mabe, 2000). However, these two indicators are not robust enough to determine the quality of publications since they are subject to bias (Law \& Chon 2007). By considering Law's (2017) comments on the uselessness of individual ranking models, the present study offers that the quality of a publication should be gauged with three main indicators: authorship structure, methodological process, and impact of publication.

Authorship structure is related to the group of authors themselves, since international collaboration in the publication (Van Raan, 1998), disciplinary diversity of authors (Barjak \& Robinson, 2008), and gender of authors (Nunkoo, Hall, \& Ladsawut, 2017) are highly influential on the quality of output. Methodological process addresses what procedure or methods are applied in the study, since each method (experimental, conceptual studies, mixed methods, traditional 
qualitative or quantitative, case studies, and review studies) requires different efforts to accomplish (Law, 2017). Impact of publication represents the quality of publishing based on impact-factor metrics. Impact factors are measured primarily by the number times a work has been cited. There are many approaches to calculate the number of citations as impact factors of publishing. For example, Journal Citation Report and Scopus Journal Metrics are commonly used.

Hybrid models: As shown in Figure 1, researchers have developed models to eliminate bias in the quantity-based and quality-based models. They include both quantity-number of publications-and quality metrics-H-index (Hirsch, 2005), G-index (Egghe, 2006), M-Quotient (Thompson, Callen, \& Nahatta, 2006), EM-index (Bihari \& Tripathi, 2017)—or some variations of these metrics (Btista, Campitelli, Konouchi, \& Martinex, 2006; Harzing \& van der Wal, 2008). These indexes are based on publication numbers and citations. Additionally, authorship network metrics are used to rank individuals. These metrics show the contributions and relationships of researchers within a given publication (Law, 2017). In practice, institutions commonly use both quantity- and quality-based approaches, along with peer reviews.

Insert Figure 1 about here

In the literature, there are several studies (Park, Phillips, Canter, \& Abbott, 2011; Rutherford \& Samenfink, 1992; Ryan, 2005; Samenfink \& Rutherford, 2002; Ye, Li, \& Law, 2013; Zhang 2015; Zhang, Lan, Qi, \& Wu, 2017; Zhao \& Ritchie, 2007) that rank researchers in the fields of hospitality and tourism. These studies use the same indicators considered in previous studies conducted in other disciplines or fields. Recently, Dev et al. (2015) introduced a model to assess faculty productivity. They considered four indicators: number of citations as quality of 
research output, number of publications as quantity of research output, citations per publication as consistency of quality research output, and citations per publication per year over an extended period as longevity of quality research. This model works as an aggregate of the average of ranking for these four indicators. Although Dev et al. (2015) stated that the model is easy, effective, and adaptable and that objectivity was maintained during its application, Law (2017) stated that "a major drawback of this assessment method is that although a scholar has left academia, the articles authored by this scholar will continue to receive citations, thereby leading to inaccurate results when comparisons are made with currently active scholars" (p. 393).

All of these methods are indeed complementary, rather than alternatives to rank or evaluate the performance of individuals. However, they can produce questionable results because they lack subjectivity, are not holistic, are discipline specific, and ignore the longevity of an individual's research life (Dev et al. 2015; Law, 2017). Therefore, the main goal of this present article is not to compare the advantages and disadvantages of the existing models but rather to introduce a holistic model minimizing subjectivity and discipline specifics and considering the longevity of individuals' research life. As researchers create their own brand, the main question is how to measure the value of this brand. Addressing this question may help us to develop a holistic individual ranking model by increasing objectivity. This effort relies on the concept of brand equity as a marketing term, which is used to measure a brand's value in the market (Aaker, 1996).

\section{Brand Equity}

Brand equity is " a set of brand assets and liabilities linked to a brand, its name, and symbol, which add to or subtract from the value provided by a product or service to a firm and/or to that firm's customers" (Aaker, 1991, p. 15). Several different perspectives exist to measure brand equity. For example, Aaker (1991) considered four components including brand loyalty, brand awareness, 
brand association, and perceived quality. Keller (1993) used brand awareness and brand image as components of brand knowledge, which is accepted as brand equity. Lassar et al. (1995) highlighted five components of brand equity: performance, social image, value, attachment, and trustworthiness. Kim, Kim, and An (2003) addressed brand equity with brand loyalty, brand awareness, perceived quality, and brand image. As shown in the literature, there is not a consensus of how to measure brand equity. Therefore, for the present study, the brand equity of a researcher may be measured with perceived quality, brand image, and brand loyalty since the other components - brand association and brand awareness - are implicitly considered in brand perceived quality and brand loyalty, respectively (Chahal \& Bala, 2012). Each of these components is discussed in more detail in the following section.

\section{METHODOLOGY}

\section{Proposed Researcher's Brand Equity Index}

This study proposes a new model to rank and evaluate individual's research performance. This is a holistic model that can increase objectivity in the ranking and performance appraisal by extending metrics. This model is called Researcher's Brand Equity Index (RBEI). The proposed RBEI model includes four components, including perceived quality, brand loyalty, brand image, and longevity of individuals' research life. Perceived quality is related to a customer's overall perception of the quality of a product or services (Chahal \& Bala, 2012). In the RBEI model it is defined as publication attributes (PA), including authorship structure, methodology, and impact of publication. Brand loyalty refers to the willingness of a customer to re-buy products and services (Chahal \& Bala, 2012). In this model it is accepted as the number of times a publication has been cited $(\mathrm{CNpP})$ of a researcher, since this number may indicate how widely accepted the studies of this researcher are. Brand image is defined as "the consumers' perception of a brand as reflected 
by the brand associations held in their memory" (Chahal \& Bala, 2012, p. 347). To measure this component, the RBEI model considers the number of the researcher's official connections. In other words, the number of co-authors $(\mathrm{CoN})$ of a researcher is considered their brand image, since the collaboration number may generate greater interaction as image among collaborators and readers of researchers' studies. Longevity of an individual's research life (LR) is calculated as the difference between the time of a researcher's first publication and the present (or otherwise determined end point). The RBEI can be decomposed as follows:

$$
R B E I=\frac{C N p P * C o N * P A}{L R}
$$

Where $\mathrm{CNpP}$ is the researcher's brand loyalty, $\mathrm{CoN}$ is the researcher's image, $\mathrm{PA}$ is perceived quality of a researcher's publications, and LR is the longevity of an individual's research life. To show how the model works, a pseudo-case method is used because researchers' information in databases such as ORCID, SCOPUS, Google Scholar Analytics, Web of Science, and others is limited. Using the information from these databases may skew the results.

\section{Operationalizing RBEI}

To first implement the model, institutions or researchers should decide which publications they will include. While one way is to include all publications, institutions or researchers may want to limit the publications based on the goal of ranking and/or evaluation. For example, while refereed articles may be chosen, books, conference papers, and book chapters might not be included in the model. After deciding this, the model can be constructed with the following components.

Longevity of individuals' research life (LR) 
$L R$ is the difference between the time of a researcher's first publication among the selected publications and the current time (otherwise determined end point). RBEI can be calculated as per day, month, or year.

Citation Number per Publication of a Researcher $(C N p P)$ as the researcher's brand loyalty

The model obtains $C N p P$ by dividing the total number of citations for the selected publications of the researcher by total publication numbers. To increase the objectivity and to standardize ranking or evaluation, institutions or researchers should select one database (e.g., ORCID, SCOPUS, Google Scholar Analytics, Mendeley, Web of Science) to obtain the citation number of the researcher. The $\mathrm{CNpP}$ can be decomposed as follows:

$$
C N p P=\frac{\text { Total citation numbers }}{\text { Total publication number }}
$$

Co-authors' numbers (CoN) of a researcher as researcher's brand image

To measure CoN, we should count the number of co-authors in the selected publications. If the researcher collaborates with a researcher more than once it must be counted as one credit.

\section{Publication attributes (PA) as perceived quality}

Before calculating PA, institutions or researchers should decide how they treat publications. They should assign credits for each publication type (PT) selected at the beginning to establish the model. There are many ways to assign credit for publications. One example is presented below (Table 1). Institutions and researchers may create similar tables by considering their goals. For example, while some institutions may place a high value on books, others may put greater value on peer-reviewed journal articles. 


\section{Insert Table 1 about here}

To calculate PA, this model includes three sub-components: authorship structure, methodological process, and impact of publishing. A description of these sub-components follows. These calculations should be repeated for each publication, then total PA should be calculated.

A- Authorship structure has several dimensions:

1- Contribution level of researcher (CLR) represents how much a researcher contributes to the co-authored publication. There are two primary ways to calculate CLR. The first is to treat all researchers equally. For example, if there are four authors in a publication, the CLR for each author is $0.25(1 / 4)$. The second method is to create a weighted matrix based on the number and order of a publication's authors. An example matrix is presented in Table 2. However, institutions and researchers have flexibility to create this table to meet their goals. For example, in China and other countries, it is common to place a high value on the corresponding author in their performance evaluation process.

Insert Table 2 about here

2- Internationalization of publication team (IPT) considers whether there is at least one international co-author in co-authored publications. The main reason for this value is that internationally co-authored publications receive more citations than nationally co-authored 
publications or single publications, so act (in)directly as a reflection of quality (Nguyen, Ho-Le, \& Le, 2017). Table 3 presents an example of the IPT calculation when there are three authors: two or more authors from one institution and from one country, two or more authors from at least two different institutions from one country, and two or more authors from two or more institutions and two or more countries (Koseoglu, Okumus, Putra, Yildiz, \& Dogan, 2017).

Insert Table 3 about here

3- Disciplinary background of the publication team (DBPT) reflects whether there is at least one team member from a different disciplinary background. In other words, multidisciplinary diversity on a research team is an important indicator of the quality of the publication (Okumus, van Niekerk, Koseoglu, \& Bilgihan, 2018). Therefore, if there is at least one team member from a different discipline, such as law, the model will give one credit for those team members. If there are no differences among authors' disciplinary backgrounds, the model will not assign any credit.

4- Gender difference in the publication team (GDPT) is considered in this model since the role of gender in collaboration is impactful on the quality of the publication (Kyvik \& Teigen, 1996; Lee \& Bozeman, 2005; Melin, 2000; Myers, 1991). This is also important to encourage collaboration between genders to increase the representation of females in academic research. In this model, if the publication is coauthored between at least one male and one female, the model will assign one credit for the team members. If there is no 
collaboration among different genders in the publication, the model will not assign any credit.

5- Granted publication (GP) is valued in the model since granted projects have a robust process to generate publications. This process is influential in the quality of the publication. If the publication indicates that it is generated from a granted project, the model will assign one credit for the team members. If the publication does not indicate that it is grant funded, the model will not assign any credit.

B- Methodological process (MP): The data collection process for each publication may not be the same. For example, while researchers need considerable time for an experimental design, they may need less time for a case study of a specific business organization. Therefore, they should not be treated equally in the ranking of individuals or in a performance appraisal, as indicated by Law (2017). To calculate MP, a weighted system should be used. Table 4 presents an example of methodological processes and their weights. Institutions and researchers are flexible to create this table to suit their goals.

Insert Table 4 about here

C- Impact of publishing (IP): Each published work generates a different impact in their field. This impact level shows the quality of a publication (Elliott, 2014; Garfield, 2003; Saha, Saint, \& Christakis, 2003). However, assessing the impact of a published work is complicated. A few companies (e.g., Clarivate Analytics, SCOPUS) release citation scores of journals that are accepted in their databases. In this model, institutions and researchers 
are free to choose one of these databases to assign IP. In the model impact factor of publishing what time publication is published must be considered.

Consequently, the PA can be decomposed as follows:

$$
P A=\sum P T *(C L R+I P T+D B P T+G D P T+G P+M P+I P)
$$

\section{Pseudo Cases}

To show how the model works, this study presents two pseudo cases. The first case is related to performance appraisal in institutions, while the second case demonstrates ranking individuals in a given discipline or field.

\section{Pseudo Case 1 for performance appraisal}

Table 5 presents the coding for and RBEI calculation of a researcher's performance appraisal. The researcher's first publication was published in 1998. The current year is accepted as 2018. Within this period the researcher produced 15 publications (Column A in Table 5). Column B shows publication years. Citation numbers in the current year $(\mathrm{CN})$ were retrieved from the Web of Science database. The other columns (D, E, F, G, H, I, and J) were filled out based on the details shared in the previous section. Consequently, PA was calculated for each publication as follows:

$$
P A=L=(D *(E+F+G+H+I+J+K))
$$

\section{Insert Table 5 about here}

Table 6 demonstrates the calculation of RBEI for a researcher's performance appraisal by using data from Table 5. RBEI was calculated for the last five years in order to see the changes in the researcher's RBEIs. Institutions may use the percentages of changes to identify faculty's research performance. 


\section{Insert Table 6 about here}

\section{Pseudo Case 2 for ranking individuals}

This model is useful for ranking individuals in a given discipline or field, in this case hospitality and tourism. For example, a researcher would like to rank individuals who generated publications related to "topic A." First, the researcher must decide publication type, and then extract the publications. Second, the researcher should create a coding table (similar to Table 5) for each author published in relation to topic A. Third, the researcher should generate an RBEI score for each author from a coding table (similar to Table 6). Last, the researcher should rank the authors based on the RBEI scores.

Table 7, Table 8, and Table 9 present the coding tables of three researchers (R1, R2, and R3) who have published in relation to topic A. In this ranking, only research notes and full-text articles published in the Social Science Citation Index's journals are considered. To create the coding tables, the following codes in the current study were assigned.

\section{Insert Tables 7, 8, and 9 about here}

Table 10 presents a ranking of these three researchers based on their RBEI scores. In these cases, the order is R3, R2, and R1. In other words, R3 has the highest brand equity in the field. 
Insert Table 10 about here

\section{DISCUSSION AND CONCLUSIONS}

The present study proposed a new approach for ranking individuals in a given discipline or field and evaluating researchers' performances in an institution. This study used brand equity to establish its approach. To show how the model works, two pseudo cases were presented. This study has significant implications by introducing a new model to the field of research. These implications are discussed below.

The main contribution of this study is to introduce a new model for individuals' ranking and the performance appraisal of researchers in the fields of hospitality and tourism. Previous models have ranked researchers based on the quantity or quality of their publications, as defined by number of publications or number of times their work was cited, respectively (Dev et al. 2015; Law, 2017). The current model is more holistic since it is based on the idea of brand equity. In this model, brand equity encompasses three components: perceived quality as defined by publication attributes, perceived image as defined by number of coauthors, and perceived loyalty as defined by citation numbers per publication. Additionally, this model considers the longevity of a researcher's publication life. This model offers controllable performance indicators to researchers. For example, the previous models consider citation numbers, which researchers cannot control. In the current model, two out of three indicators ( $\mathrm{CoN}$ and PA) are controllable. Therefore, researchers may increase their brand equity score or performance by focusing on these indicators in the publication generation process.

The hospitality and tourism academic community has two important issues that have not been resolved in many years. One of them is related to conducting interdisciplinary or 
multidisciplinary research in the field, since a strong attachment to the field is one of the main barriers to interdisciplinary research (Okumus et al., 2018). Another issue is the low representation of females in the academic research community (Munar et al., 2015). This model helps to minimize these problems in academia.

The model is applicable for not only the fields of hospitality and tourism but also other disciplines. By adopting this model, a better performance appraisal system can be established. This model can be used by institutions and researchers who rank individuals in a given field. Additionally, some ranking databases such as Google Scholar Analytics, ResearchGate, Scopus and Mendeley may adapt their ranking system with this model to provide more holistic ranking models.

\section{Limitations and Future Studies}

The proposed model has a few limitations. First, to measure brand image and brand loyalty, the model considers only one indicator for each component. This highlights opportunities for researchers to identify new indicators. Second, the effects of social media in the brand equity of researchers are ignored. Researchers may develop new indicators of brand image. Third, in this model we consider citation scores of journals as one of the indicator for the performance. However, citation scores are a journal-level metric that has nothing to do with the authors and the articles in the journal, hence, future researcher may investigate their impacts on the ranking and performance assessments of researchers. Last, since our study's intent is not to rank or evaluate individual faculty members, we show how the model is useful, beneficial, and applicable rather than providing a ranking example of faculty in the fields of hospitality and tourism. These limitations provide new research questions and potential areas of study. First, this study can be repeated to 
rank individuals. Second, new, objective hybrid metrics may be developed. Finally, by developing a scale for identifying metrics of quality of research, researchers may redesign PA indicators.

\section{References}

Aaker, D. A. (1991). Managing Brand Equity, The Free Press, New York, NY.

Aaker, D. A. (1996). Measuring brand equity across products and markets. California management review, 38(3), 102-120.

Adkins, D., \& Budd, J. (2006). Scholarly productivity of U.S. LIS faculty. Library \& Information Science Research, 28(3), 374-389.

Amin, M., \& Mabe, M. (2000). Impact factors: Use and abuse. Perspectives in Publishing. ISI Journal Publishing Reports. London: Elsevier Publications.

Barjak, F., \& Robinson, S. (2008). International collaboration, mobility and team diversity in the life sciences: impact on research performance. Social Geography, 3(1), 23-36.

Benckendorff, P., \& Shu, M. L. (2019). Research impact benchmarks for tourism, hospitality and events scholars in Australia and New Zealand. Journal of Hospitality and Tourism Management, 38, 184-190.

Bihari, A., \& Tripathi, S. (2017). EM-index: a new measure to evaluate the scientific impact of scientists. Scientometrics, 112(1), 659-677.

Btista, P. D., Campitelli, M. G., Konouchi, O., \& Martinex, A. S. (2006). Is it possible to compare researchers with different scietific interests? Scientometrics, 68(1), 179-189.

Bouyssou, D., \& Marchant, T. (2016). Ranking authors using fractional counting of citations: An axiomatic approach. Journal of Informetrics, 10(1), 183-199.

Chahal, H., \& Bala, M. (2012). Significant components of service brand equity in healthcare sector. International journal of health care quality assurance, 25(4), 343-362.

Dev, C. S., Parsa, H. G., Parsa, R. A., \& Bujisic, M. (2015). Assessing faculty productivity by research impact: Introducing Dp2 Index. Journal of Teaching in Travel \& Tourism, 15(2), 93-124.

Egghe, L. (2006). Theory and practice of the g-index. Scientometrics, 69(1), 131-152.

Elliott, D. B. (2014). The impact factor: a useful indicator of journal quality or fatally flawed? Ophthalmic and Physiological Optics, 34(1), 4-7.

Furrer, O., Thomas, H., \& Goussevskaia, A. (2008). The structure and evolution of the strategic management field: A content analysis of 26 years of strategic management research. International Journal of Management Reviews, 10(1), 1-23.

Garfield, E. (2003). The meaning of the impact factor. International Journal of Clinical and Health Psychology, 3(2).

Harzing, A.-W. K., \& van der Wal, R. (2008). Google Scholar as a new source of citation analysis? Ethics in Science and Environmental Politics, 8(1), 62-71.

Hirsch, J. E. (2005). An index to quantify an individual research output. Proceedings of National Academy of Sciences, 102(46), 16569-16572.

Keller, K.L. (1993), "Conceptualizing, measuring, and managing customer-based brand equity", Journal of Marketing, Vol. 57 No. 1, pp. 1-22.

Kim, H.B., Kim, W.G. and An, J.A. (2003), "The effect of consumer-based brand equity on firms financial performance", Journal of Consumer Marketing, Vol. 20 No. 4, pp. 335-51. 
Koseoglu, M. A., Yildiz, M., \& Ciftci, T. (2018). Authorship Trends, and Collaboration Patterns in the Business Ethics Literature. Business Ethics: A European Review, 27(2), 164-177.

Koseoglu, M. A. (2018). A new approach to journal ranking: social structure in hospitality and tourism journals, International Journal of Contemporary Hospitality Management, DOI: 10.1108/ IJCHM-10-2017-0622.

Koseoglu, M. A., Okumus, F., Putra, E. D., Yildiz, M., \& Dogan, I. C. (2018). Authorship trends, collaboration patterns, and co-authorship networks in lodging studies (19902016). Journal of Hospitality Marketing \& Management, 27(5), 561-582.

Kyvik, S., \& Teigen, M. (1996). Child care, research collaboration, and gender differences in scientific productivity. Science, Technology, \& Human Values, 21(1), 54-71.

Law, R., \& Chon, K. (2007). Evaluating research performance in tourism and hospitality: The perspective of university program heads. Tourism Management, 28(5), 1203-1211.

Law, R. (2017). Ranking individuals in tourism and hospitality research. Tourism Recreation Research, 42(3), 392-397.

Li, L., Wang, X., Zhang, Q., Lei, P., Ma, M., \& Chen, X. (2014). A quick and effective method for ranking authors in academic social network. In Multimedia and ubiquitous engineering (pp. 179-185). Springer, Berlin, Heidelberg.

Lee, S., \& Bozeman, B. (2005). The impact of research collaboration on scientific productivity. Social studies of science, 35(5), 673-702.

Marchant, T. (2009). An axiomatic characterization of the ranking based on the h-index and some other bibliometric rankings of authors. Scientometrics, 80(2), 325-342.

Melin, G. (2000). Pragmatism and self-organization: Research collaboration on the individual level. Research policy, 29(1), 31-40.

Munar, A.M. et. al. (2015), The Gender Gap in the Tourism Academy: Statistics and Indicators of Gender Equality. While Waiting for the Dawn. http://www.tourismeducationfutures.org/about-tefi/gender-equity-in-the- tourism-ac

Myers, G. (1991). Politeness and certainty: the language of collaboration in an A1 Project. Social Studies of Science, 21(1), 37-73.

Nguyen, T. V., Ho-Le, T. P., \& Le, U. V. (2017). International collaboration in scientific research in Vietnam: an analysis of patterns and impact. Scientometrics, 110(2), 1035-1051.

Nunkoo, R., Hall, C. M., \& Ladsawut, J. (2017). Gender and choice of methodology in tourism social science research. Annals of Tourism Research, 63, 207-210.

Okumus, F., van Niekerk, M., Koseoglu, M. A., \& Bilgihan, A. (2018). Interdisciplinary research in tourism. Tourism Management, 69, 540-549.

Park, K., Phillips, W. J., Canter, D. D., \& Abbott, J. (2011). Hospitality and tourism research rankings by author, university, and country using six major journals. Journal of Hospitality \& Tourism Research, 35(3), 381-416.

Rickman, D. S., \& Winters, J. V. (2016). Ranking Authors and Institutions by Publications in Regional Science Journals: 2010-2014. Growth and Change, 47(2), 312-336.

Rutherford, D. G., \& Samenfink, W. (1992). Most frequent contributors to the hospitality literature. Journal of Hospitality \& Tourism Research, 16(1), 23-39.

Ryan, C. (2005). The ranking and rating of academics and journals in tourism research. Tourism Management, 26, 657-662.

Saha, S., Saint, S., \& Christakis, D. A. (2003). Impact factor: a valid measure of journal quality?. Journal of the Medical Library Association, 91(1), 42. 
Samenfink, W. H., \& Rutherford, D. G. (2002). Most frequent contributorsto the hospitality literature: A ten-year update. Journal of Hospitality \& Tourism Education, 14(3), 5-15.

Soutar, G. N., Wilkinson, I., \& Young, L. (2015). Research performance of marketing academics and departments: An international comparison. Australasian Marketing Journal $(A M J), 23(2), 155-161$.

Thompson, D. F., Callen, E. C., \& Nahata, M. C. (2009). New indices in scholarship assessment. American Journal of Pharmacological Education, 73(6), 111-112.

Van Raan, A. (1998). The influence of international collaboration on the impact of research results: Some simple mathematical considerations concerning the role of selfcitations. Scientometrics, 42(3), 423-428.

Yang, Z., Hong, L., Yin, D., \& Davison, B. D. (2015). Ranking Authors with Learning-To-Rank Topic Modeling. International Journal Of Innovative Computing, Information And Control, 11(4), 1295-1316.

Ye, Q., Li, T., \& Law, R. (2013). A coauthorship network analysis of tourism and hospitality research collaboration. Journal of Hospitality \& Tourism Research, 37(1), 51-76.

Zhou, D., Orshanskiy, S. A., Zha, H., \& Giles, C. L. (2007, October). Co-ranking authors and documents in a heterogeneous network. In Data Mining, 2007. ICDM 2007. Seventh IEEE International Conference on (pp. 739-744). IEEE.

Zhang, J. (2015). Tourism research co-authorship networks in China. Journal of China Tourism Research, 11(4), 424-439.

Zhang, L., Lan, C., Qi, F., \& Wu, P. (2017). Development pattern, classification and evaluation of the tourism academic community in China in the last ten years: From the perspective of big data of articles of tourism academic journals. Tourism Management, 58, 235-244.

Zhao, W., \& Ritchie, J. R. B. (2007). An investigation of academic leadership in tourism research: 1985-2004. Tourism Management, 28(2), 476-490. 


\section{Quantity-based models}

\section{Objective}

\section{Subjective}

Publication

Peer reviewes;

Publication

numbers; citation

indexes; authorship

Subjective

network metrics
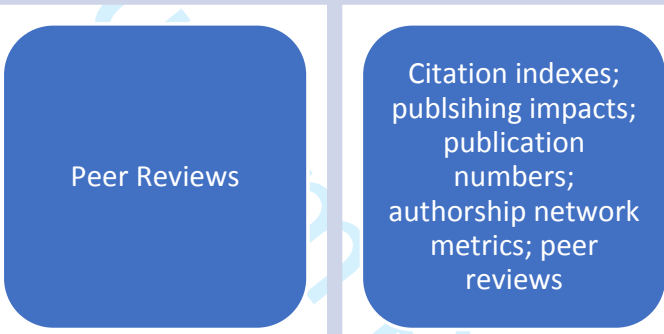

Quality-based models

indexes; authorship

network metrics;

publsihing impacts

Objective

\section{Figure 1. Hybrid individual ranking models}

Source: Developed based on the following studies Dev et al. (2015) and Law (2017) 
Table 1: Type of publication (PT) and assign credits

Publication Type Assign credits

Full text article, book, 1

Research note, chapter in an edited book $\quad 0.6$

Conference proceedings

0.3

Others

0.1 
Table 2. Value for CLR

\begin{tabular}{llllll}
\hline Author Number & \multicolumn{3}{l}{ Author Order } & & \\
& 1st & 2nd & 3rd & 4th & $\begin{array}{l}\text { 5th or } \\
\text { higher }\end{array}$ \\
\hline 1 Author & 1 & - & - & - & \\
2 Authors & 0.65 & 0.35 & - & - & \\
3 Authors & 0.55 & 0.30 & 0.15 & & \\
4 Authors & 0.55 & 0.25 & 0.125 & 0.075 & \\
5 or more authors $(\mathrm{n})$ & 0.55 & 0.25 & 0.10 & 0.050 & $0.05 /(\mathrm{n}-4)$ \\
\hline
\end{tabular}


Table 3: IPT and assign credits

\begin{tabular}{ll}
\hline IPT Type & Assign credits \\
\hline Two or more authors from at least two & 1 \\
or more institutions and at least two or & \\
more countries & \\
Two or more authors from at least two 0.6 \\
different institutions from one country \\
Two or more authors from one 0.3 \\
institution and from one country
\end{tabular}


Table 4: MP and assign credits

\begin{tabular}{ll}
\hline MP & Assign credits \\
\hline $\begin{array}{l}\text { Experimential desing, or mix methods, or longidituinal methods } \\
\text { Qualitaitve study, or quatitattive study, or case study, or conceptual }\end{array}$ & 0.7 \\
studies & 0.4 \\
Tradational review studies & 0.7 \\
\hline
\end{tabular}


Table 5. Coding for RBEI Calculation of a researcher's performance appraisal

\begin{tabular}{|c|c|c|c|c|c|c|c|c|c|c|c|}
\hline $\begin{array}{l}\text { Publication } \\
\text { No } \\
\text { A }\end{array}$ & $\begin{array}{l}\text { Publication } \\
\text { Year } \\
\text { B }\end{array}$ & $\begin{array}{l}\text { Citation } \\
\text { number in } \\
\text { the Current } \\
\text { Year }(\mathrm{CN}) \\
\text { C }\end{array}$ & $\begin{array}{l}\mathrm{PT} \\
\mathrm{D} \\
\end{array}$ & $\begin{array}{l}\text { CLR } \\
\mathrm{E}\end{array}$ & $\begin{array}{l}\text { IPT } \\
\mathrm{F}\end{array}$ & $\begin{array}{l}\text { DBP } \\
T \\
\text { G } \\
\end{array}$ & $\begin{array}{l}\text { GDP } \\
\mathrm{T} \\
\mathrm{H} \\
\end{array}$ & $\begin{array}{l}\text { GP } \\
\text { I }\end{array}$ & $\begin{array}{l}\text { MP } \\
\mathrm{J} \\
\end{array}$ & $\begin{array}{l}\mathrm{IP} \\
\mathrm{K}\end{array}$ & $\begin{array}{l}\text { PA } \\
\mathrm{L}\end{array}$ \\
\hline 1 & 1998 & 50 & 1 & 1 & - & - & - & - & 0.7 & 0.66 & 2.36 \\
\hline 2 & 1999 & 6 & 0.6 & 1 & - & - & - & - & 0.4 & - & 0.84 \\
\hline 3 & 1999 & 9 & 0.3 & 0.65 & 0.3 & - & - & - & 0.7 & - & 0.50 \\
\hline 4 & 2003 & 50 & 0.1 & 0.35 & 0.3 & - & - & - & 0.7 & - & 0.14 \\
\hline 5 & 2003 & 30 & 1 & 0.3 & 0.3 & - & - & - & 0.7 & 2.3 & 3.60 \\
\hline 6 & 2006 & 65 & 1 & 0.15 & 0.6 & 1 & - & - & 0.7 & - & 2.45 \\
\hline 7 & 2006 & - & 1 & 1 & - & - & - & - & 0.7 & 3 & 4.70 \\
\hline 8 & 2006 & - & 0.6 & 0.65 & 1 & 1 & 1 & - & 0.7 & - & 2.61 \\
\hline 9 & 2009 & 4 & 0.3 & 0.65 & 1 & - & - & - & 0.7 & - & 0.71 \\
\hline 10 & 2010 & 150 & 0.3 & 0.08 & 0.3 & - & - & - & 0.7 & - & 0.32 \\
\hline 11 & 2013 & 360 & 1 & 0.25 & 0.3 & - & - & - & 0.7 & - & 1.25 \\
\hline 12 & 2014 & 3 & 1 & 0.13 & 1 & - & - & - & 0.7 & 0.99 & 2.82 \\
\hline 13 & 2015 & 30 & 0.6 & 0.15 & 1 & - & 1 & - & 0.7 & - & 1.71 \\
\hline 14 & 2015 & 1 & 1 & 1 & - & - & - & - & 0.7 & - & 1.70 \\
\hline 15 & 2018 & 5 & 1 & 0.25 & 0.3 & - & - & - & 0.7 & - & 1.25 \\
\hline Total & & 763 & - & 7.6 & 6.4 & 2 & 2 & - & 10.2 & 6.95 & 26.94 \\
\hline
\end{tabular}


Table 6. Calculation of RBEI for a researcher's performance appraisal

\begin{tabular}{llllll}
\hline RBEI & $\begin{array}{l}\text { RBEI } \\
\text { for 2014 }\end{array}$ & $\begin{array}{l}\text { RBEI } \\
\text { for 2015 }\end{array}$ & $\begin{array}{l}\text { RBEI } \\
\text { for 2016 }\end{array}$ & $\begin{array}{l}\text { RBEI } \\
\text { for 2017 }\end{array}$ & $\begin{array}{l}\text { RBEI } \\
\text { for 2018 }\end{array}$ \\
\hline Year of first publication & 1998 & 1998 & 1998 & 1998 & 1998 \\
Current year & 2014 & 2015 & 2016 & 2017 & 2018 \\
LR as year $($ Current year- Year offirst & & & & & \\
publication +1$)$ & 17 & 18 & 19 & 20 & 21 \\
LR as month $\left(L R^{*} 12\right)$ & 204 & 216 & 228 & 240 & 252 \\
LR as day $(\mathrm{LR} * 365)$ & 6205 & 6570 & 6935 & 7300 & 7665 \\
CNpP $(\Sigma C N / \Sigma P u b l i c a t i o n ~ N o)$ & 60.58 & 54.14 & 54.14 & 54.14 & 50.87 \\
CoN & 3 & 5 & 5 & 5 & 6 \\
PA $(D *(E+F+G+H+I+J+K))$ & 22.28 & 25.69 & 25.69 & 25.69 & 26.94 \\
RBEI per year & 238.23 & 386.41 & 366.07 & 347.77 & 391.56 \\
RBEI per month & 19.85 & 32.20 & 30.51 & 28.98 & 32.63 \\
RBEI per day & 0.65 & 1.06 & 1.00 & 0.95 & 1.07 \\
Change \% & - & 62.20 & -5.26 & -5.00 & 12.59 \\
\hline
\end{tabular}


Table 7. Coding for RBEI Calculation of ranking of R1

\begin{tabular}{|c|c|c|c|c|c|c|c|c|c|c|c|}
\hline $\begin{array}{l}\text { Publication } \\
\text { No } \\
\text { A }\end{array}$ & $\begin{array}{l}\text { Publication } \\
\text { Year } \\
\text { B }\end{array}$ & $\begin{array}{l}\text { Citation } \\
\text { number in } \\
\text { the } \\
\text { Current } \\
\text { Year }(\mathrm{CN}) \\
\text { C }\end{array}$ & $\begin{array}{l}\mathrm{PT} \\
\mathrm{D}\end{array}$ & $\begin{array}{l}\text { CLR } \\
\mathrm{E}\end{array}$ & $\begin{array}{l}\text { IPT } \\
\text { F }\end{array}$ & $\begin{array}{l}\text { DBPT } \\
\text { G }\end{array}$ & $\begin{array}{l}\text { GDPT } \\
\mathrm{H}\end{array}$ & $\begin{array}{l}\text { GP } \\
\text { I }\end{array}$ & $\begin{array}{l}\text { MP } \\
\mathrm{J}\end{array}$ & $\begin{array}{l}\text { IP } \\
\mathrm{K}\end{array}$ & $\begin{array}{l}\text { PA } \\
\text { L }\end{array}$ \\
\hline 1 & 2000 & 362 & 1 & 0.3 & 0.3 & - & 1 & - & 0.4 & 1.2 & 3.20 \\
\hline 2 & 2005 & 65 & 1 & 1 & - & - & - & - & 0.7 & 2.3 & 4.00 \\
\hline 3 & 2006 & 10 & 1 & 0.15 & 0.3 & 1 & 1 & 1 & 0.7 & 2.1 & 6.25 \\
\hline 4 & 2007 & - & 0.6 & 1 & - & - & - & 1 & 0.4 & 1.6 & 2.40 \\
\hline 5 & 2010 & 23 & 1 & 0.65 & 1 & - & - & - & 0.7 & 2.5 & 4.85 \\
\hline 6 & 2015 & 45 & 1 & 1 & - & - & - & - & 0.4 & 2.6 & 4.00 \\
\hline 7 & 2017 & - & 1 & 0.075 & 1 & 1 & 1 & 1 & 1 & 2.5 & 7.58 \\
\hline 8 & 2018 & 5 & 1 & 1 & - & - & - & - & 0.7 & 3 & 4.70 \\
\hline 9 & 2018 & 15 & 0.6 & 0.55 & 0.6 & - & - & - & 0.7 & 1.5 & 2.01 \\
\hline Total & & 525.00 & - & 5.73 & 3.20 & 2.00 & 3.00 & 3.00 & 5.70 & 19.30 & 38.99 \\
\hline
\end{tabular}


Table 8. Coding for RBEI Calculation of ranking of R2

\begin{tabular}{llllllllllll}
\hline \multicolumn{1}{c}{} & \multicolumn{1}{c}{$\begin{array}{l}\text { Citation } \\
\text { number in }\end{array}$} \\
Publication & Publication & the Current & & & & & & & & \\
No & Year & Year (CN) & PT & CLR & IPT & DBPT & GDPT & GP & MP & IP & PA \\
A & B & C & D & E & F & G & H & I & J & K & L \\
\hline 1 & 1992 & 2500 & 1 & 1 & - & - & - & - & 0.7 & 3 & 4.70 \\
2 & 1994 & 600 & 1 & 0.65 & 0.3 & - & - & - & 0.7 & 2.5 & 4.15 \\
Total & & 3100 & - & 1.65 & 0.3 & - & - & - & 1.4 & 5.5 & 8.85 \\
\hline
\end{tabular}


Table 9. Coding for RBEI Calculation of ranking of R3

\begin{tabular}{llllllllllll}
\hline \multicolumn{1}{c}{$\begin{array}{l}\text { Citation } \\
\text { number in } \\
\text { the }\end{array}$} \\
Publication \\
No & $\begin{array}{l}\text { Publication } \\
\text { Current } \\
\text { Year }\end{array}$ & Year) & PT & CLR & IPT & DBPT & GDPT & GP & MP & IP & PA \\
\hline A & B & C & D & E & F & G & H & I & J & K & L \\
1 & 2015 & 100 & 1 & 0.15 & 1 & - & 1 & - & 0.7 & 3.5 & 6.35 \\
2 & 2016 & 20 & 1 & 1 & - & - & - & - & 0.7 & 1 & 2.70 \\
3 & 2018 & 1 & 1 & 0.075 & 1 & 1 & - & 1 & 1 & 2.9 & 6.98 \\
4 & 2018 & - & 1 & 0.25 & 1 & 0 & 1 & 0 & 0.7 & 3.01 & 5.96 \\
5 & 2018 & - & 1 & 0.55 & 1 & 1 & 1 & 1 & 1 & 5 & 10.55 \\
6 & 2018 & 1 & 1 & 0.65 & 1 & - & - & - & 0.7 & 2 & 4.35 \\
Total & & 122 & & 2.675 & 5 & 2 & 3 & 2 & 4.8 & 17.41 & 36.89 \\
\hline
\end{tabular}


Table 10. Calculation of RBEI for ranking of Researchers

\begin{tabular}{lccc}
\hline RBEI & $\begin{array}{c}\text { RBEI } \\
\text { for R1 }\end{array}$ & $\begin{array}{c}\text { RBEI } \\
\text { for R2 }\end{array}$ & $\begin{array}{c}\text { RBEI } \\
\text { for R3 }\end{array}$ \\
\hline Year of first publication & 2000 & 1992 & 2015 \\
$\begin{array}{l}\text { Current year } \\
\text { LR as year (Current year-Year offirst }\end{array}$ & 2018 & 2018 & 2018 \\
publication +1$)$ & 19 & 27 & 4 \\
CNpP $(\Sigma C N / \Sigma$ Publication No) & 58.33 & 1550.00 & 20.33 \\
CoN & 4 & 1 & 4 \\
PA $\left(D^{*}(E+F+G+H+I+J+K)\right)$ & 38.99 & 8.85 & 36.89 \\
RBEI per year & 478.76 & 508.06 & 750.00 \\
\hline
\end{tabular}

